\title{
能力培养与价值引领有机结合的化工原理课程思政建设
}

\author{
尹永恒 ${ }^{1,}{ }^{*}$, 李小东 ${ }^{2}$, 张红秀 1 , 牟善良 ${ }^{1}$, 夏其英 1 \\ 临沂大学化学化工学院, 山东 临沂 276005 \\ 2临沂市技师学院，山东临沂 276005
}

\begin{abstract}
摘要: 课程思政是社会主义现代化强国建设背景下提出的创新教学模式。针对工科课程特点, 结合多年化工原理教 学经验, 强化顶层设计, 进行化工原理课程思政建设。在深入挖掘重要知识点对应思政元素的基础上, 以启发式、 任务驱动式、讨论式等形式多样的教学手段将马克思主义哲学观、实践能力、创新意识、文化自信等融入化工原理 课堂教学, 传授知识的同时注重能力培养和价值引领; 此外, 对学生进行长期有效追踪, 培养学生终身学习的习惯。 利用上述 $1+2 \mathrm{~N}+1$ 模式(知识传授+能力培养、价值引领+长效追踪)进行教学实践, 力求实现润物无声的育人效果。
\end{abstract}

关键词: 课程思政; 能力培养; 价值引领; 化工原理

中图分类号: G64; O6

\section{Ideological and Political Construction of Chemical Engineering Principle Course by Combining Ability Training and Value Guidance}

\author{
Yongheng Yin ${ }^{1, *}$, Xiaodong $\mathrm{Li}^{2}$, Hongxiu Zhang ${ }^{1}$, Shanliang Mu ${ }^{1}$, Qiying Xia ${ }^{1}$ \\ ${ }^{1}$ School of Chemistry and Chemical Engineering, Linyi University, Linyi 276005, Shandong Province, China. \\ 2 Linyi Technician Institute, Linyi 276005, Shandong Province, China.
}

\begin{abstract}
Course ideology and politics is an innovative teaching model put forward under the background of the construction of a socialist modern powerful country. According to the characteristics of engineering courses, combined with years of chemical engineering principle teaching experience, the top-level design is strengthened to carry out the ideological and political construction of chemical engineering principle course. On the basis of deeply exploring the ideological and political elements corresponding to important knowledge points, the Marxist philosophy, practical ability, innovative consciousness and cultural self-confidence are integrated into the classroom teaching of chemical engineering principle by means of heuristic teaching, task driven teaching, discussion, etc. The ability training and value guidance are also emphasized while imparting knowledge. In addition, the students are effectively tracked in a long time to cultivate students' habit of lifelong learning. The above $1+2 \mathrm{~N}+1$ mode (knowledge impartment + ability training and value guidance + long term tracking) is carried out to achieve the gradual and accumulative education.
\end{abstract}

Key Words: Course ideology and politics; Ability training; Value guidance; Chemical engineering principle

中国特色社会主义进入新时代, 我国的发展也步入新阶段。在新时代背景下共筑中华民族伟大 复兴梦, 教师要利用好课堂教学这个主渠道, 使理论课程与思想政治同向同行 ${ }^{[1]}$, 将知识传授与价 值引领相结合 ${ }^{[2]}$, 以落实立德树人的根本任务。

培养专业能力强、勇于创新、具有家国情怀和国际视野的卓越人才是教师义不容辞的责任 ${ }^{[3]}$ 。

收稿: 2021-11-08; 录用: 2021-12-30; 网络发表: 2022-02-14

“通讯作者, Email: yin_yongheng@126.com

基金资助: 临沂大学 “课程思政” 示范课程建设项目(K2020SZ027, K2020SZ029) 
化工原理是化学工程与工艺、应用化学、材料工程、制药工程等专业的重要课程之一, 起到由基础 课到专业课、由理到工的桥梁作用 ${ }^{[4]}$ 。除了传授知识, 该课程还着重培养学生理论结合实践的能力 和设计能力, 为将来从事科研或生产打下坚实基础 ${ }^{[5]}$ 。目前已有较多高校教师对化工原理的 “思政 教学” 进行了尝试与探索, 根据所发表的相关教学论文, 笔者总结了本课程的思政教育框架: (1) 培 养爱国主义情怀和文化自信 ${ }^{[6]}$; (2) 培养工匠精神和科学精神 ${ }^{[7]}$; (3) 增强安全意识 ${ }^{[8]}$; (4) 强化环保 理念 ${ }^{[9]}$ 。在此基本思路的基础上, 笔者结合工科类专业的特点及化工原理课程的性质, 将能力培养 和价值引领有机结合, 采用传授知识、培养能力、引领价值、教育终身这一层层递进的方法进行课 程思政建设, 力求实现全程育人、全方位育人，能为其他理工科类课程的思政建设提供参考和借鉴。

\section{1 思政建设整体思路}

化工原理课程包含诸多重要的基本概念、计算公式等, 还对常用化工设备进行了介绍。通过多 年化工原理教学, 笔者发现学生在本课程学习过程中普遍存在以下 3 个问题: (1) 学生对课程内容理 解不深刻, 难以抓住重点; (2) 学生对纯理论知识兴趣不高, 更无法将理论与实践相结合; (3) 学生 对所学内容死记硬背, 遗忘迅速。针对上述 3 个问题, 以思政建设为主线, 对化工原理课程的教学进 行了顶层设计: 首先, 深入挖掘课程重点内容涉及的思政元素(如表1所示), 并将思政元素与重点内 容巧妙结合, 在有限的课时内帮助学生高效理解、掌握重点理论知识; 其次, 利用启发式、任务驱 动式、讨论式、案例式等多种生动活泼的教学手段将思政元素融入化工原理课堂教学, 在传授知识 的同时进行能力培养和价值引领, 将实践能力、创新能力、文化自信、工匠精神等思政教育全面映 射到整个教学过程中; 再次, 思想政治教育与理论学习相似, 课程过后教师应继续给予学生充分关 注, 促使学生养成终身学习的习惯。基于上述思路, 笔者提出 $1+2 \mathrm{~N}+1$ 理念, 即以知识传授为基础, 以能力培养和价值引领为核心, 以长效追踪为责任。课程利用 $1+2 \mathrm{~N}+1$ 理念进行全程、全方位育人, 达到润物无声的育人效果。整体思路如图1所示。

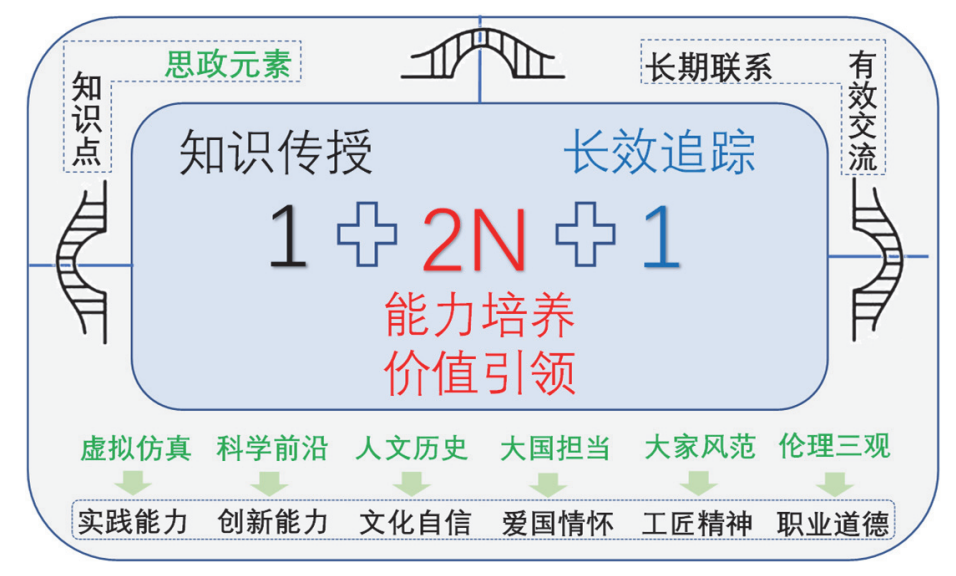

图1 思政建设整体思路示意图

\section{2 思政教学的主要内容及实施方法}

\section{1 善用马克思主义哲学观, 强化实践操作能力}

自然科学的进步是马克思主义哲学形成和发展的前提, 而马克思主义哲学对自然科学的发展具

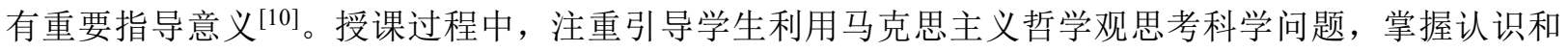
实践之间的辩证关系, 培养学生理论联系实际的能力。 
大学 化学 Univ. Chem. 2022, 37 (10), 2111021 (3 of 7)

\section{表1 化工原理专业知识与思政元素的有机融合}

\begin{tabular}{|c|c|c|}
\hline 章节 & 思政映射与融入点 & 思政教学设计示例 \\
\hline 绪论 & $\begin{array}{l}\text { 1. 化工过程的操作原理(现象和本质的关系) } \\
\text { 2. 单位与量纲(精益求精的工匠精神) } \\
\text { 3. 物料及能量衡算(对立统一规律) } \\
\text { 4. 单元操作的选择 (一分为二的观点) }\end{array}$ & $\begin{array}{l}\text { 1. 问题引导式教学: (1) 你在日常生活中见过哪些加工过程? (2) 我们 } \\
\text { 平时食用的糖和盐是怎么来的? 用到了哪些加工过程? (3) 这些加工过 } \\
\text { 程的原理有什么共性? 通过三个问题层层递进, 培养学生透过现象看本 } \\
\text { 质的能力 } \\
\text { 2. 启发式教学: 针对混合液体分离, 可采用哪些单元操作? 它们各有什 } \\
\text { 么优缺点? 进而向学生渗透多元化发展战略 }\end{array}$ \\
\hline 流体流动 & $\begin{array}{l}\text { 1. 流体静力学方程(爱国主义精神) } \\
\text { 2. 伯努利方程的推导(偶然性和必然性的关 } \\
\text { 系) } \\
\text { 3. 伯努利方程的应用(文化自信和科学的怀 } \\
\text { 疑精神) } \\
\text { 4. 流量的测定(四个自信) }\end{array}$ & $\begin{array}{l}\text { 1. 任务驱动式教学: 请计算当光缆铺设在大海 } 5000 \text { 米深处时受到海水 } \\
\text { 的压强是多少? 介绍我国举世瞩目的光缆铺设及根服务器架设 “雪人计 } \\
\text { 划”, 培养学生的爱国主义情怀 } \\
\text { 2. 体验式教学: (1) 播放大禹治水相关视频, 假如你生在夏朝, 能否像 } \\
\text { 禹一样解决水泛滥的问题? 讲述中华民族智慧, 培养学生的文化自信; } \\
\text { (2) 很多人都曾经使用伯努利方程来解释飞机起飞, 是否合理? 为什 } \\
\text { 么? 培养学生科学的怀疑精神 }\end{array}$ \\
\hline $\begin{array}{c}\text { 流体输送 } \\
\text { 机械 }\end{array}$ & $\begin{array}{l}\text { 1. 液体输送机械分类(敢于担当、勇于奉献的 } \\
\text { 精神) } \\
\text { 2. 离心泵的气蚀现象(原因与结果的关系) } \\
\text { 3. 压缩机工作原理(持之以恒的钻研精神) }\end{array}$ & $\begin{array}{l}\text { 1. 讨论式教学: 观看我国南水北调工程相关视频片段, 集体讨论实现南 } \\
\text { 水北调需要用到哪些输送机械? 参与南水北调工程移民所体现的“舍小 } \\
\text { 家为大家” 精神教会了你什么? } \\
\text { 2. 引导式教学: 介绍西气东输工程及其对我国能源结构的影响, 思考气 } \\
\text { 体是如何运输的 } \\
\text { 3. 启发式教学: } 1902 \text { 年英国海军的 “眼镜蛇号” 驱逐舰下水试航仅 } 12 \\
\text { 小时, 螺旋桨就被严重破坏, 这是什么原因造成的? 引导学生分析原因 } \\
\text { 与结果之间的关系 }\end{array}$ \\
\hline 沉降与过滤 & $\begin{array}{l}\text { 1. 非均相物系的分离(生态文明建设、爱国主 } \\
\text { 义精神) } \\
\text { 2. 过滤设备(科技创新) }\end{array}$ & $\begin{array}{l}\text { 1. 任务驱动式教学: 针对目前时常出现的雾䨪污染, 查阅文献, 探索口 } \\
\text { 罩过滤雾䨪的工作原理及遏制雾䨪的根本途径, 鼓励学生利用生态文明 } \\
\text { 建设思想指导生产实践 } \\
\text { 2. 启发式教学: 简述新型材料如石墨烯在小分子过滤分离领域的进展, } \\
\text { 鼓励学生紧跟科学前沿, 助力科技创新 }\end{array}$ \\
\hline 传热 & $\begin{array}{l}\text { 1. 热量传递的基本方式(发展的观点) } \\
\text { 2. 傅里叶定律(百折不挠的奋斗精神) } \\
\text { 3. 传热系数(安全教育) }\end{array}$ & $\begin{array}{l}\text { 1. 体验式教学: 大家分别尝试用炭火、烤箱和空气炸锅进行肉类烹制, } \\
\text { 哪种熟的更快? 请同学们总结这三种方法传热方式的区别, 学会用发展 } \\
\text { 的眼光看待客观世界 } \\
\text { 2. 讨论式教学: 观看 } 3 \cdot 21 \text { 响水化工企业爆炸事故相关报道, 讨论爆炸发 } \\
\text { 生可能的原因, 提醒学生安全是生产实践的重中之重 }\end{array}$ \\
\hline 吸收 & $\begin{array}{l}\text { 1. 吸收剂的选择(绿色环保理念) } \\
\text { 2. 菲克定律(联系的观点) } \\
\text { 3. 液气比(节能减排理念) }\end{array}$ & $\begin{array}{l}\text { 1. 翻转课堂教学法: 请学生查阅相关文献资料, 上台讲解甲烷法二硫化 } \\
\text { 碳生产工艺中 } \mathrm{H}_{2} \mathrm{~S} \text { 的吸收剂选择方案, 培养学生绿色环保的工程理念 } \\
\text { 2. 类比式教学: 将菲克定律、牛顿黏性定律及傅里叶定律进行类比, 引 } \\
\text { 导学生用联系的观点进行学习 }\end{array}$ \\
\hline 蒸馏 & $\begin{array}{l}\text { 1. 蒸馏的概念及分类(传统文化熏陶) } \\
\text { 2. 双组份连续精馏(职业道德培养) } \\
\text { 3. 板式塔(人生态度与价值取向) }\end{array}$ & $\begin{array}{l}\text { 1. 体验式教学: 学习蒸馏酒传统酿造工艺, 接受优秀传统文化的熏陶 } \\
\text { 2. 讨论式教学: 假酒中常含有甲醇, 如何分离出乙醇中的甲醇? 播放假 } \\
\text { 酒危害相关视频, 培养学生的职业道德和社会责任感 }\end{array}$ \\
\hline
\end{tabular}




\begin{tabular}{|c|c|c|}
\hline 章节 & 思政映射与融入点 & 思政教学设计示例 \\
\hline \multirow[t]{5}{*}{ 干燥 } & 1. 干燥方法(否定之否定规律) & 1. 小组合作式教学: 分小组讨论干燥方法有哪些, 讲述干燥技术的发展 \\
\hline & 2. 湿空气性质(传统文化熏陶) & 史, 引导学生体会科学技术从低级到高级、从简单到复杂的周期性螺旋 \\
\hline & & 式的发展过程 \\
\hline & & 2. 启发式教学: 二十四节气中的白露是什么含义? 它意味着空气的性 \\
\hline & & 质发生了哪些转变？通过传统文化培养学生的文化自信 \\
\hline \multirow[t]{3}{*}{ 萃取 } & 萃取分离的进展(文化自信) & 案例教学: 㾏疾是一种困扰人类数千年的疾病, 我国科学家屠呦呦将青 \\
\hline & & 蒿素应用在疮疾治疗中使得患者死亡率显著降低, 讨论青蒿素是如何提 \\
\hline & & 取出来的, 培养学生的文化自信 \\
\hline \multirow[t]{2}{*}{ 结晶 } & 结晶动力学(美学熏陶) & 直观演示教学法: 播放晶体规整微观结构及色彩缤纷的晶体形貌, 使学 \\
\hline & & 生接受美学熏陶 \\
\hline
\end{tabular}

本课程所涉及的马克思主义哲学主要包括五对范畴(内容和形式、现象和本质、原因和结果、可 能性和现实性、偶然性和必然性)、三大规律(对立统一规律、量变质变规律、否定之否定规律)和三 个观点(联系的观点、发展的观点、一分为二的观点)。例如讲解管路的试差计算时, 提示学生只有找 准初始值并使用合适的迭代方法才能使结果从可能性向现实性转化; 讲解雷诺准数时, 通过实验装 置向学生展示流速逐渐增大时流动类型从层流到湍流的过渡, 引导学生体会量变与质变之间的转化 规律; 将牛顿黏性定律、傅里叶定律和菲克定律进行对比, 指出公式中的推动力分别是速度差、温 度差和浓度差, 引导学生善用联系的方法进行总结和记忆。

相比理科课程, 工科课程具有更强的实践性 [11]。授课过程中指导学生亲自操作虚拟仿真软件(如 图2所示), 引导学生将理论知识与生产实践相结合。例如, 讲解精馏塔时, 指导学生操作虚拟工厂 中的精馏设备进行乙醇-水混合物分离, 学生通过检查生产设备稳定性是否符合要求、全面分析生产 流程, 在实践中发现问题、分析问题、解决问题, 进而丰富、拓展理论知识。此外, 课堂上适当引 入化工厂安全事故相关的报道和视频(如 $3 \cdot 21$ 响水化工企业爆炸事故、内蒙古东兴化工 $4 \cdot 24$ 爆炸事故 等), 引导学生分析事故原因, 提高谨慎细微的观察能力, 强化安全生产意识。

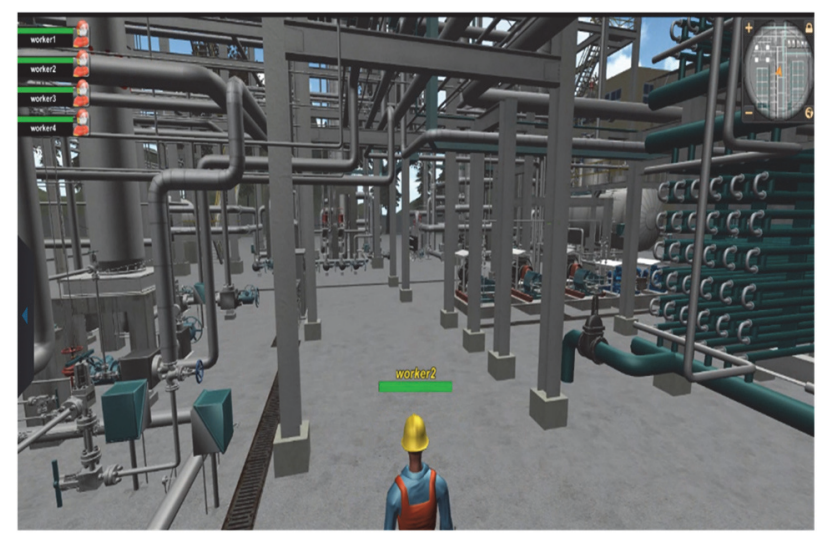

图2 虚拟仿真实践操作界面

\section{2 聚焦科学前沿, 激发创新意识}

在中国特色社会主义新时代背景下, 科技创新成为发展的第一动力。作为一名高校教师, 面对 朝气蓬勃、具有强大创新潜力的年轻人, 更要担负起鼓励学生科技创新的使命。授课过程中注重引 
入与化工原理相关的科学前沿研究, 倡导学生利用创新手段为绿色化工发展和生态文明建设贡献自 己的力量。

例如, 讲解辐射传热时, 介绍国际热核聚变实验堆计划, 即人造太阳计划(如图3a所示), 如果发 明一种可以承受上亿度温度的装置并且稳定控制氞和気聚变, 就能像太阳一样给人类提供无限清洁 的能源 ${ }^{[12]}$; 此外, 进一步介绍世界领先的传热材料, 科罗拉多大学的尹晓波和杨容贵发明了一种无 需制冷剂、无需电力就可以为建筑降温的薄膜, 其工作原理为 “辐射冷却” , 相关成果发表在世界 顶级科研杂志《科学》上(如图3a所示)。通过科学前沿成果介绍, 激发学生的创新热情和意识。流体 输送机械章节, 介绍国际上先进的自动化技术(如图3b所示), 讲述这一新兴技术如何在社会经济发 展中发挥重要作用。结合化工领域的溶剂回收再利用、绿色经济路线等工程目标, 引导学生树立生 态文明理念, 利用创新思维走可持续发展道路。
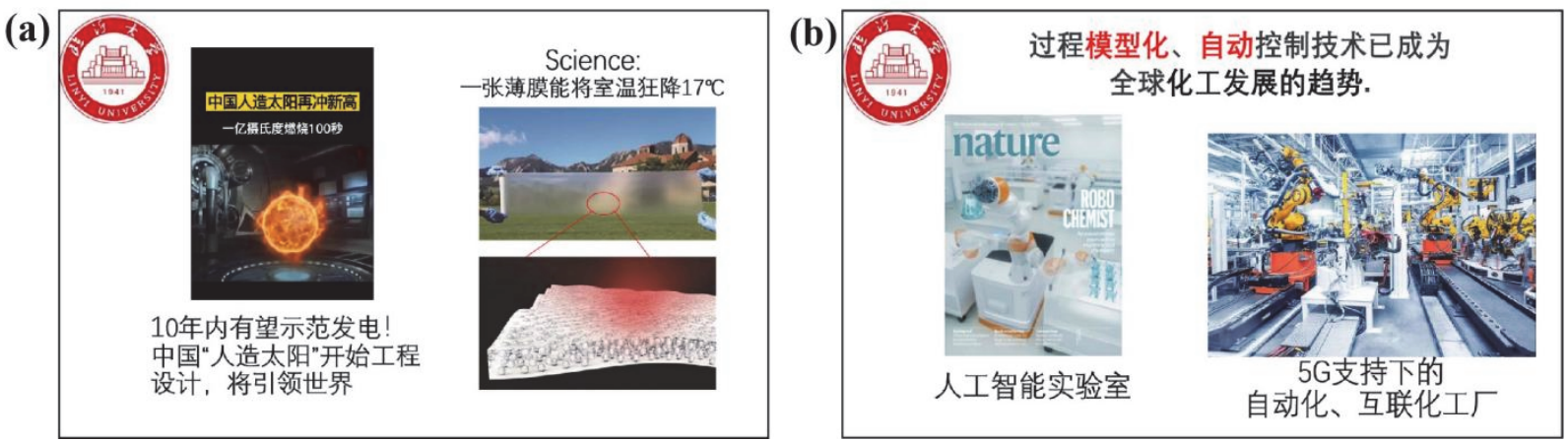

图3 课堂融入科学前沿教育

\section{3 增强文化自信, 培养爱国情怀}

建国以来, 尤其是改革开放 40 年来, 我国的科技实力显著提升, 部分领域已进入世界先进行 列 ${ }^{[13]}$, 为经济发展、社会进步、改善民生和国家安全提供了重要支撑。教学中, 结合我国优秀传统 文化, 引入科学家在峥嵘岁月中不忘初心、科技报国的事迹, 使学生在学习专业知识的同时增强 “四 个意识”，坚定 “四个自信”，培养爱国主义情怀。

例如, 在讲述简单蒸馏之前, 引入我国悠久的酿酒历史及蒸馏酒的发展过程(如图4a), 学生通过 思考酿造、蒸馏两种制酒工艺的区别体会蒸馏的操作原理, 鼓励学生课下阅读古典酿酒书籍, 如《北 山酒经》, 将文化自信厚植学生内心。

充分利用与中国科学家有关的经验公式或相关原理进行教学, 如讲解物料衡算时, 请学生讨论 侯氏制碱法与索维尔制碱法相比有哪些优势, 引入中国重化学工业的开拓者侯德榜先生的事迹; 讲 解摩擦系数时, 请学生留意顾毓珍公式; 总结精馏设备时, 介绍化学工程学家、教育家苏元复的故

(a)

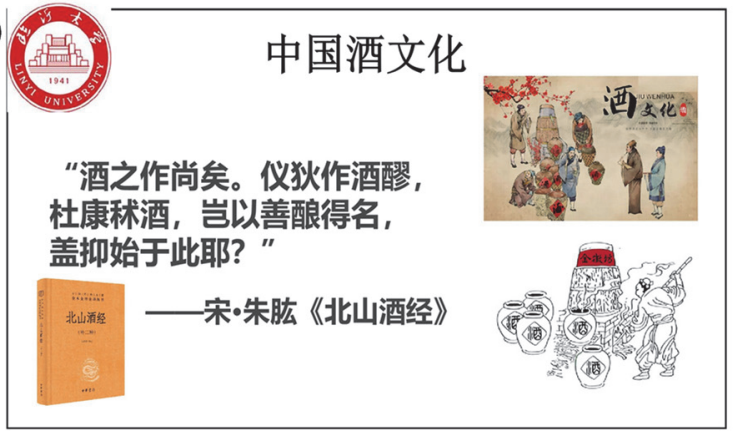

(b)

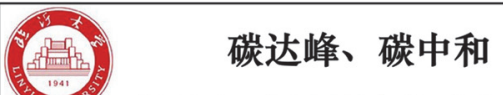

中国宣布：力争2030年前二氧化碳排放达到 峰值, 努力争取2060年前实现碳中和。

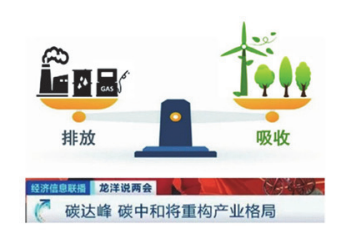

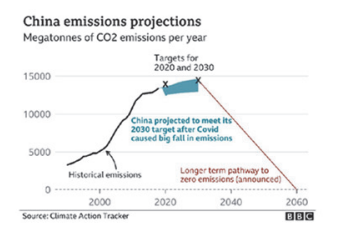

图4＼cjkstart课堂植入文化自信培养及爱国主义教育 
事。通过图片、短视频的形式讲述我国老一辈科学家为振兴中华所做的卓越贡献, 培养学生的爱国 主义情怀。

注重结合时事热点进行教学, 如讲解吸收速率时, 向学生介绍我国两会期间提出的 “碳达峰” “碳中和” 概念(如图4b), 这是我国向全世界作出的郑重承诺, 在课堂上让学生牢记自己在全国环保 事业中所承担的重要角色; 恒压过滤一节, 请同学们讨论口罩的动力学原理, 讲述抗击新冠疫情期 间，中国向世界提供的口罩超过 700 亿只，充分展现了大国担当，进一步激发学生的民族自豪感。

\section{4 学习工匠精神, 恪守职业道德}

从最初的工艺试差应用, 到单元操作的提出、“三传一反” 的凝练, 这两百多年的时间里, 无 数的科学家和工程师为经典理论、定律、方程的创立和化工的发展做出了不可磨灭的贡献 ${ }^{[14]}$ 。将相 关科学家顽强拼搏、勇攀高峰的精神映射进理论教学, 对培养学生正确的世界观、人生观和价值观 具有重要作用。

如讲解伯努利方程时, 介绍数学史上最著名的家族一一伯努利家族, 丹尼尔·伯努利对一切知识 孜孜不倦的学习精神以及谦虚的品质对学生的人格培养有很好的启示作用; 热传导一节, 引入法国 著名数学家、物理学家傅里叶的励志故事; 介绍压缩机时, 利用翻转课堂请学生展示压缩机在空调 中的重要作用, 并介绍 “空调之父” 威利斯·开利对空调的钻研探索之路。通过这些科学家、发明家 的相关故事, 向学生传达对待科学应具备百折不挠、持之以恒的钻研精神。

爱因斯坦曾说: “科学究竟给人带来幸福还是灾难, 全取决于人自己, 而不取决于工具。”科 学技术注定是一把双刃剑, 在课堂上传授知识的同时, 教师们也应告诫学生进行科学研究要守好伦 理之门。例如在讲解气体吸收时, 以哈伯制氨法中二氧化碳和氢气的吸收分离为例, 引入德国化学 家弗里茨·哈伯的故事, 作为第一个从空气中制造出氨的科学家, 哈伯为加速世界农业的发展做出了 重要贡献, 然而, 一战中哈伯又研制毒气并用于战争中, 造成百万人伤亡, 成为人类的罪人, 通过 此类故事引导学生思考应该怎样进行科学研究, 这一过程对教育学生守住伦理道德底线、恪守职业 道德具有重要意义。

\section{3 化工原理课程思政建设成效}

笔者已经连续两年对化工原理课程进行思政建设, 并通过授课中问卷调查、提问以及结课后线 上交流、研讨等多种方式对思政建设成效进行了考查。最近一次的问卷调查结果显示, $96.4 \%$ 的学生 认为通过该课程的学习, 培养了自身的爱国情怀和工匠精神, 其中 $92.9 \%$ 的学生表示该课程的价值引 领没有 “硬植入” , 91.1\%的学生认为课程的思政教育 “非常自然” ; 通过课上讨论及配套的实验课 程, 发现学生的实践能力有了大幅度提高, 也有相当一部分同学开始注意到需要提高自身创新能力, 有志通过进一步读书深造完善自我。利用长效追踪机制, 与部分学生进行长期有效交流, 统计发现, 结课一年后, 约 $80 \%$ 的学生能够记得教师在授课过程中讲过的科学家相关事迹, 其中 $70 \%$ 表示对相应 的知识点印象深刻。这充分表明, 课程思政建设对知识传授、能力培养和价值引领起到了良好的作 用。然而, 将学生培养成具有终身学习意识的卓越人才, 仍是我们继续努力的目标和方向。

\section{4 结语}

本门课程深入挖掘了马克思主义哲学、工匠精神、职业道德、爱国情怀、文化自信、工程安全、 探索创新等思政元素, 并通过现场教学、师生互动、现代信息技术等多种手段将其有机融入教学过 程, 在传授知识的同时实现实践、创新能力培养和全方位价值引领, 达到思政教育目标的同时强化 课程总体目标, 使学生潜移默化接受思政教育, 达到 “润物细无声” 的效果。希望通过对本课程的 系统建设, 使学生在强化综合能力的同时, 锤炼高尚品格, 成为实现中国梦的伟大推动者、重要参 与者。 
[1] 王世革, 陈政. 广州化工, 2021, 49 (6), 131.

[2] 潘鹤林, 黄婕, 卢杨, 朱忆天. 化工高等教育, 2020, 37 (1), 110.

[3] 陈金金, 董亮亮, 涂国云, 张春芳, 白云翔. 大学化学, 2021, 36 (11), 2105066.

[4] 李卫宏, 周惠燕, 王芙蓉. 化学教育(中英文), 2021, 42 (2), 24.

[5] 刘伟, 刘丽英, 刘清雅. 中国大学教学, 2021, No. 4, 44 .

[6] 胡否, 吴真, 周守勇, 李梅生, 许家兴, 贺爱永, 徐继明. 广州化工, 2020, 48 (9), 190.

[7] 杨智勇, 王菁, 赵建章, 蔡香丽. 山东化工, 2020, 49 (7), 213 .

[8] 许前会, 武宝萍, 朱平华, 张秋荣. 云南化工, 2020, 47 (11), 196.

[9] 党明岩, 宋䓉韬. 江西化工, 2019, No. 5, 38.

[10] 王伟光. 哲学研究, 2010, No. 9, 3.

[11] 潘鹤林, 黄婕, 吴艳阳, 刘玉兰, 朱忆天. 大学化学, 2019, 34 (11), 113.

[12] 王丽娜. 科技导报, 2017, 35 (1), 155.

[13] 李娜娜. 中国科技论坛, 2020, No. 9, 9.

[14] 余海荣, 刘军, 程昌敬. 广州化工, 2021, 49 (9), 205. 